\title{
Patterns of genetic variation in the endangered European mink (Mustela lutreola L., 1761)
}

\author{
Maria Teresa Cabria ${ }^{1,2}$, Elena G. Gonzalez ${ }^{3}$, Benjamin J. Gomez-Moliner ${ }^{1}$, Johan R. Michaux ${ }^{2,4}$, Dimitry Skumatov ${ }^{5}$,
} Andreas Kranz ${ }^{6}$, Pascal Fournier ${ }^{7}$, Santiago Palazon ${ }^{8}$ and Rafael Zardoya ${ }^{3^{*}}$ (D)

\begin{abstract}
Background: The European mink (Mustela lutreola, L. 1761) is a critically endangered mustelid, which inhabits several main river drainages in Europe. Here, we assess the genetic variation of existing populations of this species, including new sampling sites and additional molecular markers (newly developed microsatellite loci specific to European mink) as compared to previous studies. Probabilistic analyses were used to examine genetic structure within and between existing populations, and to infer phylogeographic processes and past demography.

Results: According to both mitochondrial and nuclear microsatellite markers, Northeastern (Russia, Estonia and Belarus) and Southeastern (Romania) European populations showed the highest intraspecific diversity. In contrast, Western European (France and Spain) populations were the least polymorphic, featuring a unique mitochondrial DNA haplotype. The high differentiation values detected between Eastern and Western European populations could be the result of genetic drift in the latter due to population isolation and reduction. Genetic differences among populations were further supported by Bayesian clustering and two main groups were confirmed (Eastern vs. Western Europe) along with two contained subgroups at a more local scale (Northeastern vs. Southeastern Europe; France vs. Spain).

Conclusions: Genetic data and performed analyses support a historical scenario of stable European mink populations, not affected by Quaternary climate oscillations in the Late Pleistocene, and posterior expansion events following river connections in both North- and Southeastern European populations. This suggests an eastern refuge during glacial maxima (as already proposed for boreal and continental species). In contrast, Western Europe was colonised more recently following either natural expansions or putative human introductions. Low levels of genetic diversity observed within each studied population suggest recent bottleneck events and stress the urgent need for conservation measures to counteract the demographic decline experienced by the European mink.
\end{abstract}

\section{Background}

The European mink (Mustela lutreola, L. 1761) is a riparian mustelid that used to occupy most of the main river drainages in Europe. The rapid decline of this species throughout its distribution range $[1,2]$ is the result of its dependence on natural river courses that limits its dispersal capacity [3, 4], and factors such as habitat fragmentation, over-hunting, pollution, anthropogenic barriers, as well as the presence of the invasive American mink (Neovison vison), a direct ecological competitor potentially spreading diseases to which $M$. lutreola is

\footnotetext{
* Correspondence: rafaz@mncn.csic.es

${ }^{3}$ Departamento de Biodiversidad y Biología Evolutiva, Museo Nacional de Ciencias Naturales, CSIC, José Gutiérrez Abascal, 2, 28006 Madrid, Spain Full list of author information is available at the end of the article
}

vulnerable [5-8]. Consequently, the European mink is listed as one of the most endangered mammals in Europe (IUCN Red List of Threatened Species, http://www.iucnredlist.org) [9]. In an effort to promote its long-term conservation, several measures are under consideration (i.e., captive breeding, restoration and/or reintroduction programs). These measures seek to maintain the genetic diversity of wild populations of this endangered species.

At present, the European mink consists of scattered isolated populations restricted to three areas: Northeastern Europe (NE; Belarus and Russia), Southeastern Europe (SE; Danube and Dniester deltas in Romania and Ukraine), and Western Europe (W; Southwest France and Northern Spain) $[6,9]$. To date, genetic studies on the
Ciomed Central 
European mink $[10,11]$ have examined mitochondrial (mt) DNA control region, and six microsatellite loci originally isolated from other mustelid species. These studies pointed to NE Europe as the most likely glacial refuge since the population in this region showed the highest haplotype diversity. In addition, the extremely low genetic diversity of the $\mathrm{W}$ population was interpreted as evidence for a recent colonization of this region by few animals, possibly after human introduction [10]. However, the specimens examined in these studies $[10,11]$ were mostly from France and results require further confirmation based on a more complete and even sampling effort across the current distribution range of the species.

In the present study, we combined molecular data (both mtDNA and nuclear microsatellites) from Michaux et al. [10] with new molecular data obtained from additional specimens from Russia, Belarus, Romania, and Spain. We also used five new species-specific microsatellite loci isolated from European mink [12] on all samples. With these new data and recently developed Bayesian analysis methods, our goals were to gain further insight into: i) the current genetic structure of the European mink; ii) the phylogeographic processes associated with the glacial refuge and post-glacial colonization of the species, and the origin of the $\mathrm{W}$ population; iii) the role of river drainages in shaping the current species distribution; and iv) the existence of population genetic bottlenecks caused by the effects of human impact. By improving our understanding of the evolutionary processes leading to the current population structure of the European mink, the results of this study are useful to shape future management strategies for the conservation of this endangered species.

\section{Results}

\section{Mitochondrial DNA analyses}

Genetic variability-Standard population genetic analyses

A fragment of the mtDNA control region was amplified and sequenced in 157 specimens (Fig. 1). The trimmed alignment (after removing indels) was 476-bp long and yielded 17 distinct haplotypes defined by 17 variable sites. Sequence variability of mtDNA was characterised by nucleotide and haplotype diversities of $\pi=0.005 \pm$ 0.003 and $h=0.857 \pm 0.014$, respectively (Table 1 ). The mtDNA dataset I revealed highest levels of genetic diversity $(\pi=0.004$ and $h=0.862)$ and a high percentage (92.31 \%) of private haplotypes for NE populations (mostly Russia). In contrast, SE populations were characterised by four haplotypes (of which, only Mlh16 was shared with Russia) and low mtDNA variation $(\pi=0.0019$ and $h=0.352$ ). Lowest haplotype diversity was detected for $\mathrm{W}$ populations, where all individuals shared the same haplotype, which was not found in Eastern European (NE and $\mathrm{SE}$ ) populations. Analyses based on the mtDNA dataset II identified rivers North Dvina, West Dvina and Volga (NE populations) as significantly contributing to mean genetic diversity levels (Table 1).

\section{Phylogenetic analyses and population genetic structure}

The reconstructed phylogeny showed a general lack of resolution. The only strongly supported clade included haplotypes from the SE populations (Fig. 2a). The haplotype network (Fig. 2b) revealed that most NE haplotypes are connected to each other (generally differing by only one mutational step) in a star-like fashion with a central haplotype (Mlh16), which is also found in SE populations. SE and W populations showed private haplotypes, which are connected to the network through missing intermediate haplotypes. Reconstruction of the haplotype network using statistical parsimony rendered similar results (data not shown).

High levels of haplotype frequency differentiation $\left(\Phi_{\mathrm{ST}}\right.$ values ranged from 0.586 to 0.879$)$ were found among $\mathrm{NE}, \mathrm{SE}$, and $\mathrm{W}$ populations (mtDNA dataset I), with all comparisons being statistically significant (Additional file 1). A more detailed analysis comparing the different sampling localities also showed significant $\Phi_{\mathrm{ST}}$ values, ranging from 0.143 (Russia vs. Belarus + Estonia) to 0.742 (Belarus + Estonia vs. W) (data not shown). Similarly, significant genetic differentiation was also detected among the tested river basins (mtDNA dataset II; Additional file 1).

The hierarchical analysis of molecular variance (AMOVA) strongly supported genetic differentiation of the European mink, but failed to detect geographic structuring of East $(\mathrm{NE}+\mathrm{SE})$ vs. W populations or $\mathrm{NE}$ vs. SE populations (Additional file 2). The genetic variability was mainly explained by variation among populations within each region. Similarly, no evidence of genetic structuring was observed among regions when pooling individuals according to the different drainage basins (Additional file 2).

\section{Historical demography}

Tajima's D, Fu's Fs and R2 statistic tests failed to reject the null hypotheses (Ho) of non-expanding (stable) populations, as was shown by the general pattern of nonsignificant $(P>0.10)$ low negative $F$ s and Tajima's D values (Table 1). However, most $\mathrm{D}$ and Fs values were negative indicating an excess of rare variants and suggesting that the overall population size may have fluctuated in the past.

Coalescent-based reconstructions of the demographic history of the NE and SE populations inferred from BSP analyses revealed histories of long-term stability in effective population size until approximately $5 \mathrm{Kyr}$ for the $\mathrm{NE}$ populations, and a recent demographic expansion period in the SE populations during the Last Glacial Maximum, corresponding to a population increase of more than $30 \%$ (Fig. 3). 


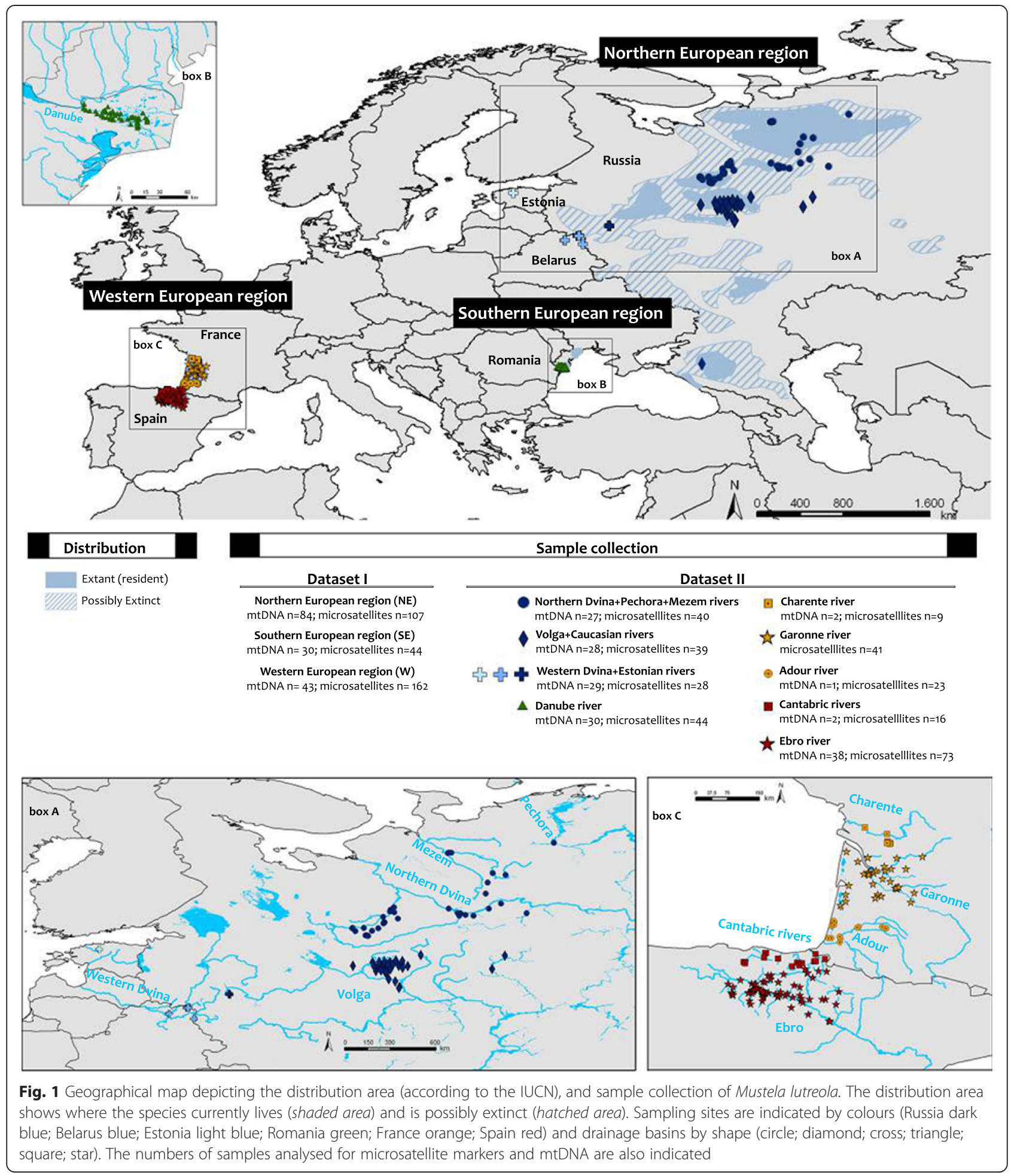

\section{Microsatellite results}

Genetic variability-Standard population genetic analyses

Microsatellite alleles were obtained from a total of 313 specimens (Fig. 1). Estimates of null allele frequencies were moderate to low $(<0.2)$, and $\mathrm{F}_{\mathrm{ST}}$ values obtained from the null-allele corrected and original data sets were very similar (data not shown). Thus all loci were used in further analyses.

No evidence of linkage disequilibrium was found as none of the corresponding exact tests remained significant 
Table 1 MtDNA diversity estimates and neutrality test results for European mink dataset $I^{a}$ and dataset $\|^{b}$. The variables provided are: number of sampled individuals $(n)$, number of observed haplotypes $\left(N_{h}\right)$ with private haplotypes $\left(P_{h}\right)$ in brackets, and haplotype $(h)$ and nucleotide $(\pi)$ diversities with standard deviations (SD) in brackets. None of the neutrality tests performed were significant $(P>0.05)$

\begin{tabular}{|c|c|c|c|c|c|c|c|}
\hline \multirow[b]{2}{*}{ Sampling sites } & \multirow[b]{2}{*}{$\mathrm{n}$} & \multirow[b]{2}{*}{$N_{h}\left(P_{h}\right)$} & \multicolumn{2}{|c|}{ Diversity indices } & \multicolumn{3}{|c|}{ Neutrality test } \\
\hline & & & $h(\mathrm{SD})$ & $\pi(\mathrm{SD})$ & Tajima's D & Fu's Fs & $R 2$ \\
\hline All individuals tested & 157 & 17 & $0.857(0.014)$ & $0.005(0.003)$ & -0.399 & -3.316 & 0.075 \\
\hline \multicolumn{8}{|l|}{ mtDNA dataset I } \\
\hline East (Russia, Belarus, Estonia, Romania) & 114 & $16(16)$ & $0.869(0.014)$ & $0.005(0.003)$ & -0.550 & -3.380 & 0.075 \\
\hline Northeast (Russia, Belarus, Estonia) & 84 & $13(12)$ & $0.862(0.016)$ & $0.004(0.003)$ & -1.008 & -3.501 & 0.067 \\
\hline Southeast (Romania) & 30 & $4(3)$ & $0.352(0.103)$ & $0.0019(0.0015)$ & -0.890 & 0.012 & 0.087 \\
\hline \multicolumn{8}{|l|}{ mtDNA dataset II } \\
\hline North Dvina & 27 & 6 & $0.775(0.047)$ & $0.004(0.002)$ & 0.817 & -0.287 & 0.165 \\
\hline Volga & 28 & 4 & $0.717(0.050)$ & $0.003(0.002)$ & 0.515 & 0.865 & 0.154 \\
\hline West Dvina & 29 & 10 & $0.810(0.064)$ & $0.005(0.003)$ & -1.117 & -2.177 & 0.086 \\
\hline
\end{tabular}

aecause of the presence of only a single haplotype in the West, this region is not included in the table

${ }^{\mathrm{b}}$ Results for the Danube river correspond to those obtained for the southeastern region

after Bonferroni correction $(P=0.000182 ; n=275$ comparisons). Thus, microsatellite loci were considered statistically independent.

Microsatellites were polymorphic in all tested populations with the exception of locus MLUT04, which presented a single allele within the Spanish samples. A total of 64 alleles (ranging from two to 10 alleles per population) were obtained. Private alleles were found in both Eastern $(\mathrm{NE}+\mathrm{SE})$ and $\mathrm{W}$ populations but at different percentages, $52.46 \%$ and $9.38 \%$, respectively (Table 2 ). Low levels of microsatellite genetic variability (A: 5.818; $\mathrm{H}_{\mathrm{O}}=0.430 ; \mathrm{H}_{\mathrm{E}}=0.578$ ) were detected. After Bonferroni correction, only the Spanish population showed significant departures $(P<0.001, n=55$ comparisons $)$ from HWE for the following loci: MVIS22 $\left(\mathrm{F}_{\mathrm{IS}}=0.265\right)$, MVIS72 $\left(F_{I S}=0.274\right)$, and MER41 $\left(F_{I S}=0.422\right)$, due to a heterozygote deficit.

Consistent with mtDNA results, $\mathrm{W}$ and NE populations (mostly Russian) had the lowest and highest levels of genetic variability, respectively, whereas SE populations showed intermediate values (Table 2). Individuals pooled according to their drainage distribution (microsatellite dataset II) showed the highest genetic variability in the Volga, North and West Dvina rivers. The individuals from the Danube showed intermediate genetic variability and within the French and Spanish rivers, the Adour and the Ebro showed the highest and lowest genetic variability values, respectively.

\section{Patterns of population genetic structure}

The Bayesian clustering procedure [13] obtained the highest likelihoods for $k=4$ (Fig. 4a). Individuals from the NE (Russia, Belarus + Estonia) populations clustered as only one inferred group with an assignment probability (Q) higher than 0.93 (Fig. 4b). Most individuals from Romania, France, and Spain were significantly assigned to three different inferred clusters $(Q>0.90)$. In contrast, the uppermost hierarchical level of structure was shown at $k=2$ when the modal value of $\Delta \mathrm{k}$ was estimated [14] (data not shown). In this case, the inferred clusters clearly corresponded to the two main regions $(\mathrm{NE}+\mathrm{SE}$ versus W) analyzed, each of which showed a very high average proportion of membership ( $Q>0.95)$ (not shown). The same results were obtained when a Dirichlet prior process was assumed [15]. The SAMOVA analysis showed the highest $\mathrm{F}_{\mathrm{CT}}$ value $\left(\mathrm{F}_{\mathrm{CT}}=0.904, P=0.015\right)$ for an arrangement of populations in $k=4$ clusters, corresponding to the lineages identified by STRUCTURE.

Consistent with the mtDNA analysis, all but one pairwise $\mathrm{F}_{\mathrm{ST}}$ comparisons based on microsatellite data showed significant values both at the region (microsatellite dataset I) and drainage (microsatellite dataset II) levels. The only exception was the comparison between Garonne and Charentes rivers in France $\left(\mathrm{F}_{\mathrm{ST}}=0.001 ; P\right.$ $<0.0014)$, whose populations are geographically close (Additional file 3). Similar patterns were obtained with the $\mathrm{R}_{\mathrm{ST}}$ estimates (Additional file 3). In this case, all comparisons were significant except those involving Garonne and Charentes $\left(\mathrm{R}_{\mathrm{ST}}=0.005 ; P>0.0014\right)$, and the North Dvina and Volga $\left(R_{\mathrm{ST}}=0.004 ; P>0.0014\right)$ rivers in France and NE, respectively (Additional file 3).

The hierarchical AMOVA identified significant geographic structuring $\left(\mathrm{F}_{\mathrm{ST}}=0.224, P<0.001\right)$. However, no genetic structuring was supported when STRUCTURE results (two or four geographical groups) were considered. The genetic variation in the data set was 


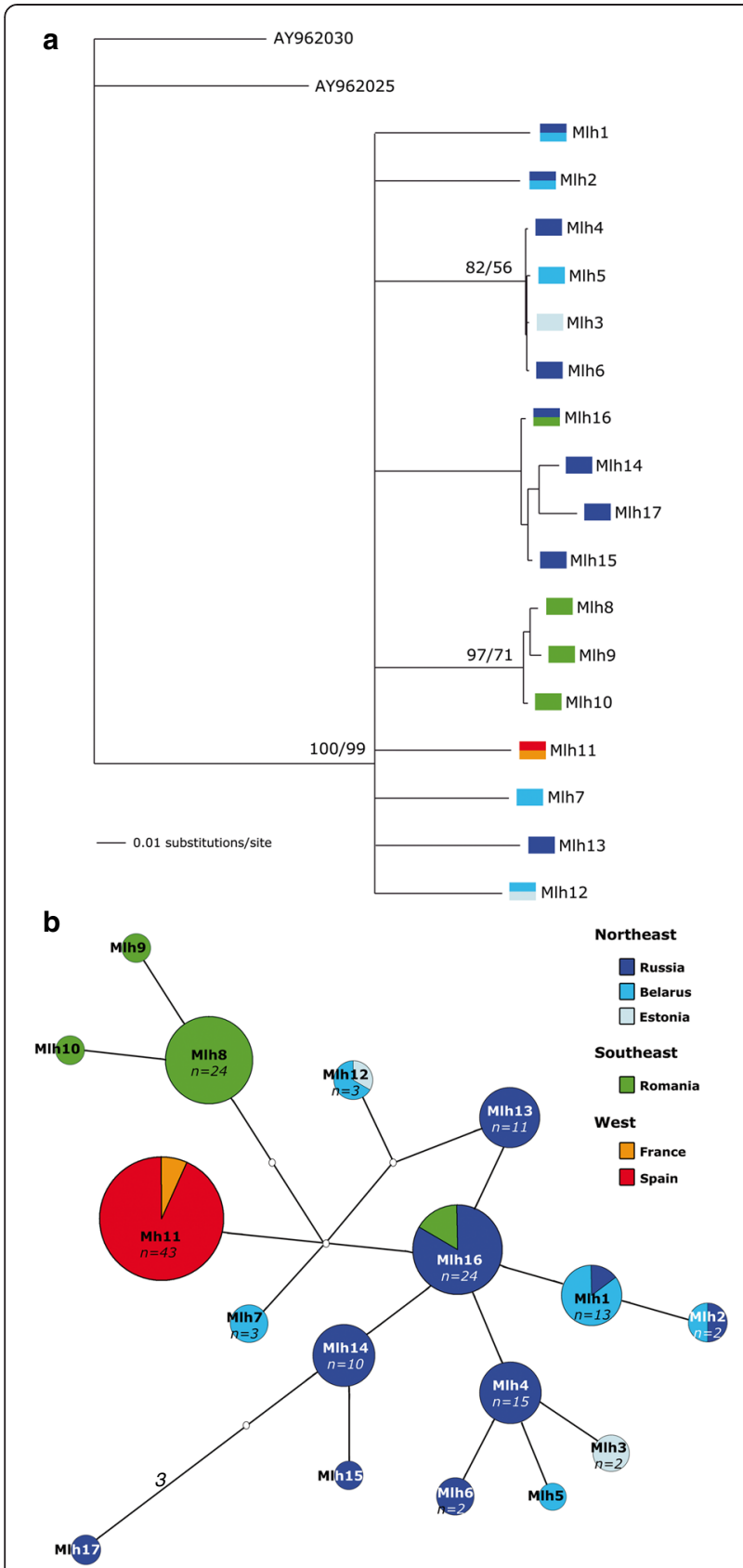

Fig. 2 Phylogenetic tree and median-joining network. (a) Phylogenetic relationships of the European mink based on mtDNA haplotype data using BI and ML. Numbers represent support for BI (BPPs, on the left) and $\mathrm{ML}$ (BPS, on the right). (b) Median-joining network showing the relationships among mtDNA haplotypes of Mustela lutreola $(\varepsilon=10)$. Circle sizes are proportional to the haplotype frequency. White circles show the missing intermediate haplotype states, and connections represent one mutation step (except for the branch indicated in italics). The geographical origin of each haplotype is indicated by different colours (see legend)

significantly explained by variation among and within populations (Additional file 4). Interestingly, genetic structuring was significant when samples were grouped according to drainage basins (Additional file 4). In agreement with other genetic analyses, FCA assigned the European mink samples to three well-defined groups, $\mathrm{W}, \mathrm{NE}$, and SE, respectively (Additional file 5 ).

\section{Reconstruction of colonization pathways for western populations}

The analysis performed under the $\mathrm{ABC}$ framework summarized by the polychotomous logistic regression method (Additional file 6) revealed that scenario number 2 had a significantly higher posterior probability (PP) value (0.40) as compared to other scenarios (Fig. 5).

Scenario 2 suggests a recent origin for $\mathrm{W}$ populations after admixture between already genetically differentiated NE and SE populations. This foundation event of the $\mathrm{W}$ population would have been followed by a posterior separation between French (FR) and Spanish (SP) populations in relatively recent times. The analyses gave estimations of divergence times among these populations (Additional file 7). However, these values are likely highly overestimated due to the large differences in allelic frequencies detected between the $\mathrm{W}$ populations associated with recent bottleneck and founder events. Therefore, we preferred to be very careful considering these estimations and not considered them as strict values in our discussion.

\section{Discussion}

The European mink (Mustela lutreola, L. 1761) is one of the most endangered mammals on the continent showing only a few scattered populations restricted to three separated regions. Human pressure (e.g., habitat fragmentation and hunting) is likely the main underlying cause of the current critical situation of European mink populations. Other factors affecting population viability such as past demographic events and the ecological dependence of the species on riparian habitats might also be responsible for local declines. The present study investigates the population genetics of the European mink based on a better survey of the distribution range of Mustela lutreola and a more representative number of specimens per locality with respect to prior studies $[10$, 11]. The different analyses performed on both $\mathrm{mt}$ and nuclear genetic data confirmed that the overall genetic variability was relatively high, as previously reported by Michaux et al. [10, 11], and comparable to the levels reported for other threatened and non-threatened mustelid species [16-23]. However, our results based on both geographic (Dataset I) and river drainage (Dataset II) sampling, indicate that this genetic variation is not homogeneously distributed throughout the species' range. Thus, Eastern European localities (NE + SE) and corresponding drainage basins (North and West Dvina, Volga 

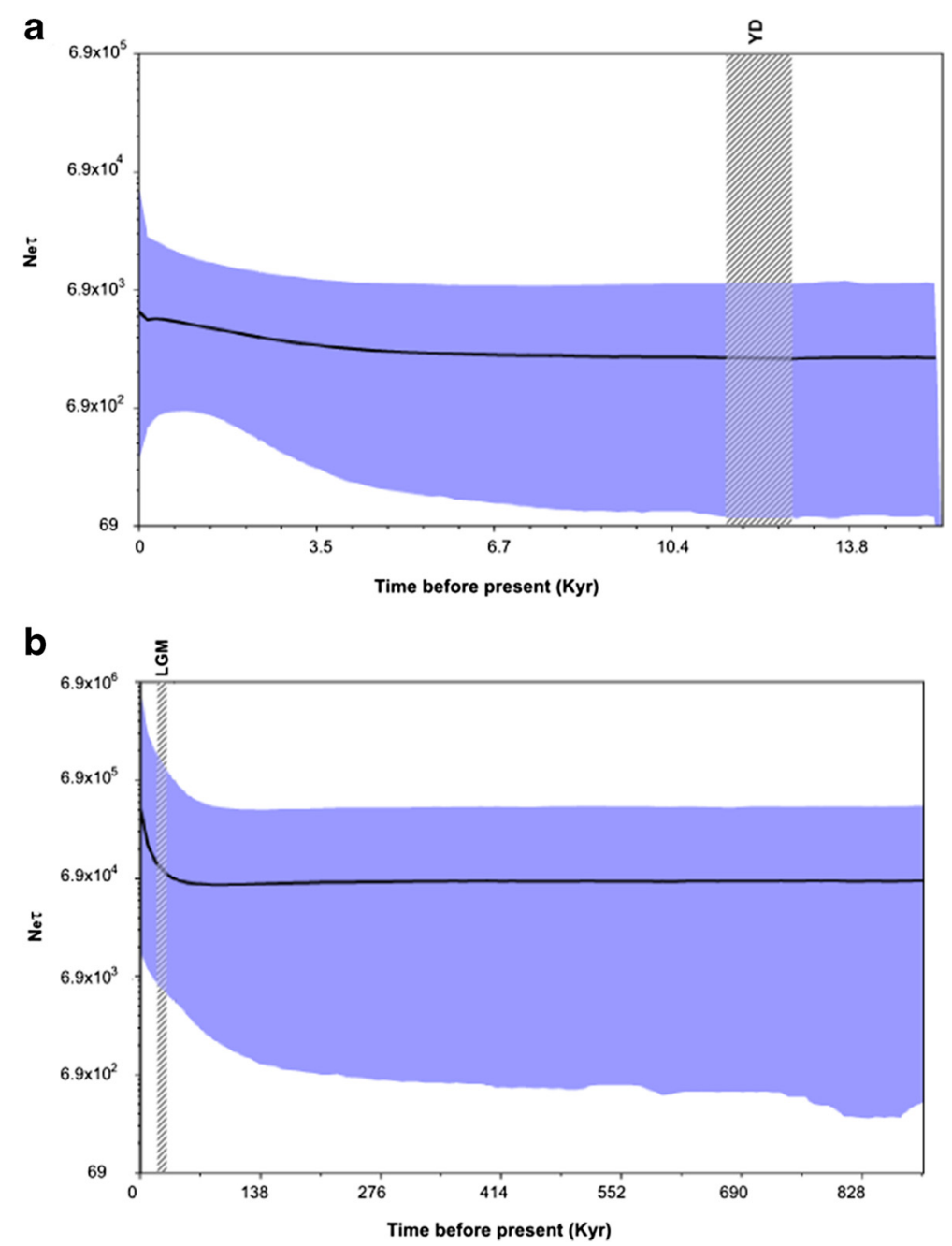

Fig. 3 Bayesian skyline plot. Bayesian skyline plot depicting the historical demography of the Northeastern (a) and Southeastern (b) European populations of Mustela lutreola based on mt haplotype data. The $y$-axis is equal to $\mathrm{N}_{\mathrm{e}} \mathrm{\tau}$, where Ne represents the effective population size and $\mathrm{\tau}$ the generation time in years. The $x$-axis represents units of time before the present in thousands of years (Kyr). The thick solid line represents the median estimated $\mathrm{Ne}$, and the coloured area shows the $95 \%$ HPD limits of $\mathrm{N}_{\mathrm{e}} \mathrm{T}$. The Last Glacial Maximum (LGM, 22-18 Kyr) and Younger Dryas interstadial (YD, 12.8-11.5 Kyr) are also indicated

and Danube rivers) revealed higher levels of genetic diversity than W localities and corresponding rivers.

\section{Relative contribution of historical and contemporary events to the genetic structure of the European mink}

At a large geographical scale, Bayesian clustering, $\mathrm{F}_{\mathrm{ST}}$ pairwise comparisons and AMOVA analyses all rejected the null hypothesis of panmixia, supporting the existence of different groups of genetic diversity among W, NE, and SE European regions. Our Bayesian clustering analysis suggests the existence of at least two main genetic units of European mink defined by the eastern $(\mathrm{NE}+\mathrm{SE})$ and $\mathrm{W}$ European populations, respectively. At a more local scale, Eastern Europe was differentiated into NE and SE populations, and Western Europe into French and Spanish populations. The FCA plotting analysis also supported this pattern. Isolation due to large habitat fragmentation produces strong genetic drift among regions, and this may ultimately result in the significant genetic differences (NE vs. SE vs. France vs. Spain) detected in this study.

However, our Bayesian $(\mathrm{ABC})$ results also indicate that the existence of these genetic units is relatively recent, and that they were historically connected after the last glaciation. In the network reconstructions, Eastern European $(\mathrm{NE}+\mathrm{SE})$ populations retained the most abundant missing intermediate haplotypes and showed the highest levels of genetic diversity, supporting the hypothesis that the European mink survived glacial periods across an extensive geographic area covering Eastern Europe around the central Russian Upland [10, 11] in additional refugia [24] to those postulated for temperate species in the 
Table 2 Genetic variability estimates for eleven microsatellite loci tested in the European mink datasets $I^{\mathrm{a}}$ and $\|^{\mathrm{b}}$. The variable provided are: number of individuals tested $(n)$, number of total alleles $\left(N_{A}\right)$, the total private allele $\left(P_{A}\right)$ with the corresponding percentage in brackets, allelic diversity (A), observed and expected heterozygosities, $\mathrm{H}_{\mathrm{O}}$ and $\mathrm{H}_{\mathrm{E}}$ respectively, and mean $\mathrm{F}_{I S}$ (Wright's statistic)

\begin{tabular}{|c|c|c|c|c|c|c|c|}
\hline Sampling sites & $n$ & $\mathrm{~N}_{\mathrm{A}}$ & $P_{A}(\%)$ & A & $\mathrm{H}_{\mathrm{O}}$ & $\mathrm{H}_{\mathrm{E}}$ & $F_{\text {IS }}$ \\
\hline All individuals tested & 313 & 64 & - & 5.818 & $0.430 \pm 0.113$ & $0.578 \pm 0.148$ & 0.255 \\
\hline \multicolumn{8}{|l|}{ Microsatellite dataset I } \\
\hline East (North and South) & 151 & 61 & $32(52.46 \%)$ & 5.546 & $0.532 \pm 0.150$ & $0.618 \pm 0.156$ & 0.141 \\
\hline Northeast & 107 & 59 & $20(33.90 \%)$ & 5.364 & $0.559 \pm 0.153$ & $0.613 \pm 0.164$ & 0.089 \\
\hline Russia & 88 & 57 & $13(22.81 \%)$ & 5.182 & $0.569 \pm 0.151$ & $0.619 \pm 0.159$ & 0.082 \\
\hline Belarus + Estonia & 19 & 42 & $2(4.76 \%)$ & 3.818 & $0.503 \pm 0.230$ & $0.54 \pm 0.207$ & 0.095 \\
\hline Southeast(Romania) & 44 & 35 & 2 (5.71 \%) & 3.182 & $0.464 \pm 0.170$ & $0.496 \pm 0.139$ & 0.065 \\
\hline West & 162 & 32 & $3(9.38 \%)$ & 2.909 & $0.336 \pm 0.161$ & $0.439 \pm 0.201$ & 0.236 \\
\hline France & 73 & 29 & $1(3.45 \%)$ & 2.636 & $0.389 \pm 0.182$ & $0.430 \pm 0.206$ & 0.095 \\
\hline Spain & 89 & 29 & 1 (3.45 \%) & 2.636 & $0.291 \pm 0.184$ & $0.353 \pm 0.215$ & 0.178 \\
\hline \multicolumn{8}{|l|}{ Microsatellite dataset II } \\
\hline North Dvina & 40 & 54 & $3(5.56 \%)$ & 4.909 & $0.563 \pm 0.188$ & $0.618 \pm 0.181$ & 0.090 \\
\hline West Dvina & 28 & 47 & $2(4.26 \%)$ & 4.273 & $0.546 \pm 0.187$ & $0.582 \pm 0.185$ & 0.064 \\
\hline Volga & 39 & 51 & 2 (3.92 \%) & 4.636 & $0.560 \pm 0.147$ & $0.598 \pm 0.146$ & 0.065 \\
\hline Charentes & 9 & 25 & - & 2.273 & $0.364 \pm 0.223$ & $0.409 \pm 0.213$ & 0.117 \\
\hline Garonne & 44 & 33 & 1 (3.03 \%) & 3 & $0.373 \pm 0.186$ & $0.426 \pm 0.205$ & 0.128 \\
\hline Adour & 23 & 26 & - & 2.364 & $0.451 \pm 0.233$ & $0.432 \pm 0.198$ & -0.045 \\
\hline Cantabrian rivers & 16 & 25 & - & 2.273 & $0.317 \pm 0.193$ & $0.382 \pm 0.252$ & 0.176 \\
\hline Ebro & 73 & 29 & - & 2.636 & $0.285 \pm 0.185$ & $0.337 \pm 0.210$ & 0.155 \\
\hline
\end{tabular}

${ }^{a}$ Because of the low number of samples from Estonia, this locality was analyzed in combination with individuals from Belarus

${ }^{\mathrm{b}}$ Results for the Danube river correspond to those obtained for the southeastern region

Mediterranean region [25]. Several authors suggested the Eastern Palearctic around Siberia and Southern Ural Mountains as well as possible areas of central Europe as glacial refuges for the survival of different species during cold stages of the Late Pleistocene [24, 26, 27]. The species ascribed to these refuges (e.g., Picea abies [28], Rana arvalis [29] or Ips typographus [30]) have in common their continental or boreal distribution. Subfossil remains of European mink dated as Upper Würmian and Holocene have been cited for the Moscow region, Estonia, Latvia Poland, Ukraine and Romania [1,31], supporting past wide presence of the species in eastern regions. Moreover, open landscapes of tundra and steppe forests of the Late Valdai (Würm) Glaciation in the Central Russian Upland region are also in favor of such refuge hypotheses, as these habitats are particularly adequate for the survival of European mink [32, 33]. The possibility that M. lutreola was able to survive glacial maxima in Eastern Europe is further supported by the nonsignificant results of performed neutrality tests. Bayesian skyline plot analysis also indicated a scenario of stable populations, suggesting that the demographic course of European mink was not seriously affected by Quaternary climate oscillations in the Late Pleistocene.

The AMOVA results showing no significant geographic structuring among regions strengthen the hypothesis of a rapid post-glacial expansion. According to the refuge theory [25, 34], rapid population expansion from refugia during interglacial periods would have entailed serial bottlenecking with progressive loss of allelic diversity, resulting in less population genetic diversity among the most recently colonised places. The starlike pattern for the European mink NE population inferred here is consistent with this theory. However, the patterns displayed by SE and W populations depart from expectations and additional events are needed to explain these patterns (see below).

The current distribution of European mink is closely linked to river courses, which could be the main force driving the historical and current genetic structuring of the species. We tested such hypothesis, and significant differentiation was detected associated to river drainages. However, this result could be an artifact since inclusion of populations with low numbers of individuals such as the Danube River population may have lead to overestimation in the detection of genetic structure of the species. In fact, 
a

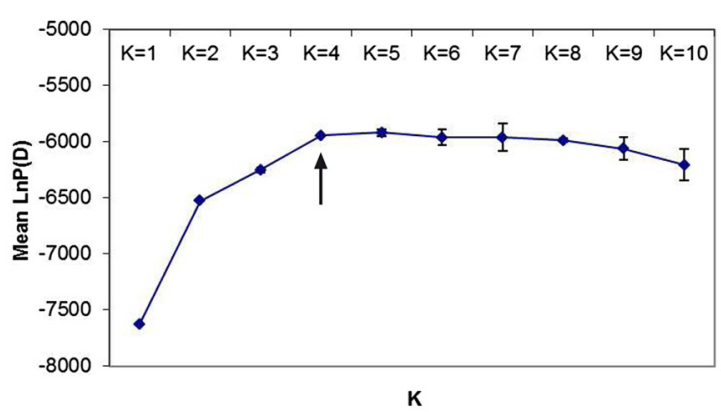

b

microsatellite dataset I
Northeastern Europe Southeastern Europe Western Europe

Russia
microsatellite dataset II
the clustering results for European mink populations obtained using STRUCTURE. (a) Detecting the number of populations as
ighest posterior probability (mean LnP[D]) over the number of clusters $k$ ( $k=4)$. (b) Each individual is represented as a vertical
$k$ segments whose length is related to their membership proportions to each inferred $k$ cluster. The subdivision according to

AMOVA results on samples clustered according to different rivers were non significant. This suggests that European mink may be capable of dispersal across river drainages over long periods of time, provided that natural conditions are favorable, which still seems to be the case in some parts of the NE region, and likely was throughout Europe during the rapid postglacial expansion of European mink. In particular, field studies corroborate important movement capacity of the European mink during the reproductive period in populations with low densities, when animals are looking for potential mates, moving up to 40-50 km during these periods [35].

At present, however, natural conditions in riverine habitats are not that favorable for survival in much of the distribution of the species, and the significant levels of heterozygosity excess detected together with the results of genetic bottleneck analyses suggest that European mink has suffered recent (human-mediated) genetic bottleneck processes, which might result in local extinctions. This would be consistent with the reported overall demographic decline of the species during the past century [2]. Only individuals from rivers Garonne and Ebro, as well as Belarus locality, seemed to be exceptions to the general trend of genetic depletion detected for the species. Habitat fragmentation affecting dispersal across river drainages seems to be the major force behind interrupted gene flow among populations.

The origin of the W population of European mink has been the subject of a hot debate [36-38]. Our ABC analysis favored a scenario in which Eastern populations had successive cycles of genetic differentiation (e.g., due to isolation by distance) and posterior genetic admixture (e.g., through spread across river connections). The W population would have diverged from an ancestral eastern population encompassing both NE and SE genetic pools during a period of population admixture. The alternative scenario of no genetic differentiation/ admixture cycles within the Eastern region and thus a stable and continuous distribution range of European mink over time in this region was less preferred. Afterwards, the FR and SP would have separated at both sides of the Pyrenees leading to the currently observed genetic differentiation within the $\mathrm{W}$ population.

The ultimate causes of the observed genetic uniformity of the W population could be explained by several working hypotheses. If European mink was not present in the Western region until recently, low genetic diversity could be attributed either to natural migration of European mink into Western Europe from Central Europe or to a putative human-mediated introduction of individuals from 

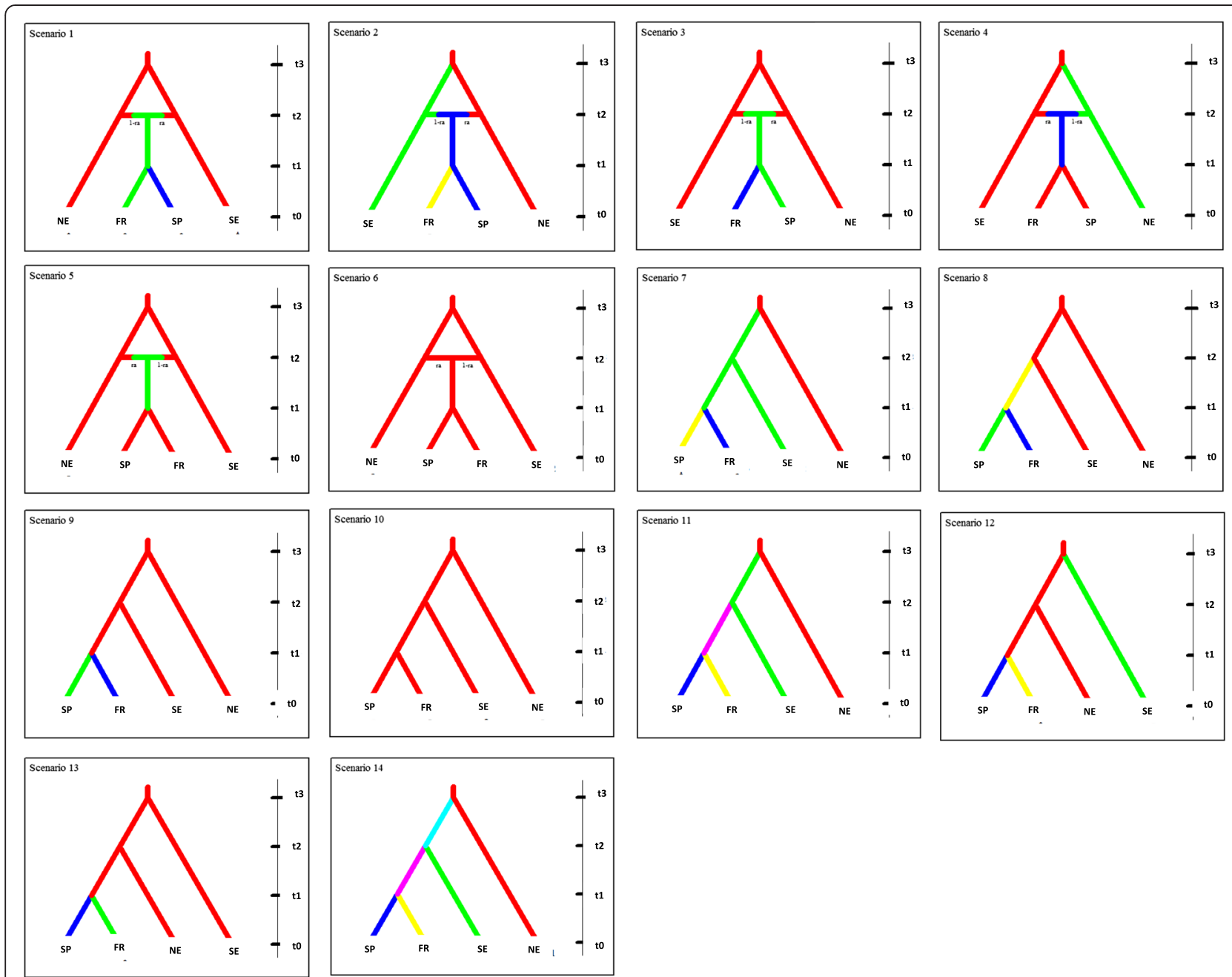

Fig. 5 Diagram of the stepwise procedure followed for approximate Bayesian computations performed using the DIYABC program. All colonization scenarios tested assumed four current populations (NE, SE, France and Spain) and their divergence from a single ancient population. The events (size variation, divergence and/or admixture) that defined each scenario are depicted as changes in the pattern (colour or shape) in the branches of each coalescent tree. Time of events $\left(T_{i}\right)$ is shown on the right. Time 0 is the sampling time of populations. The best scenario identified in each step is also highlighted (Scenario 2, PP $=0.40$ )

Central and/ or Eastern Europe. If the presence of the species in Western Europe is old enough, a rapid decline of the population in France for unknown reasons causing a severe genetic bottleneck followed by restoration of the population could also explain the observed genetic pattern. Alternatively, other more general but less obvious causes influencing also other species than the European mink could be underlying the evolutionary process. Unfortunately, the poor fossil record of European mink in the Western region and the uncertainty associated to estimated divergence times based on genetic data do not allow dating when exactly the species started inhabiting the region. Moreover, the rapid extinction process of European mink from Central Europe precludes any valid conclusions with regard to the feasibility of competing hypotheses. Future studies that may be capable of obtaining genetic data from museum specimens originated in Central Europe, as well as other focused in the population genetic structure of other related species (e.g. polecat, otter, stoat) could help discerning among the abovementioned hypotheses.

\section{Conservation strategies}

Since two-four isolated units of European mink exist, conservation criteria could be targeted at maintaining current genetic differences in these regions by managing them separately. However, our results indicate that throughout most of their evolutionary history, European mink populations were connected, and indeed likely formed a panmictic unit. Thus, the isolation of the units is viewed here as a recent human-induced event. The vast genetic differences detected among the distinct 
geographic areas are likely the result of the drastic population decline occurring during the past two centuries, although a founder effect cannot be precluded as an alternative source of the marked genetic divergence signature observed in W populations [10].

Hence, our results suggest that to return to the historical optimum of the species, European mink populations should actually be managed as a single management unit, and that strategies should be taken to promote gene flow among scattered existing populations. Actions to improve genetic connectivity are considered key to counteract inbreeding depression, as well as to preserve evolutionary potential and ensure long-term survival of endangered species [39-41]. Without such actions, the levels of genetic variability are currently so weak in some populations, that the risk of a rapid extinction is extremely high. To optimize conservation strategies, connectivity restoration programs need to minimize genetic threats arising from reduced outbreeding or loss of local adaptation [39, 42]. In addition, further in-situ actions (e.g., preserving an optimal ecological riverine niche, preventing infectious diseases, controlling American mink population) would minimize other factors increasing the extinction risk associated with the European mink [43-45].

\section{Conclusions}

Based on both mt and nuclear (microsatellite) data, we found that the European mink populations of the Eastern European region (NE and SE) hold the highest genetic diversity. In contrast, the low values of genetic polymorphism and the structure detected in the $\mathrm{W}$ populations could be the result of founder events, possibly followed by genetic depauperation. Our results suggest that European mink populations were stable during Late Pleistocene climate oscillations, expanded through river connections after the last glaciation period, and later suffered relative high levels of extinction (e.g., in central Europe). Moreover, European mink likely experienced recent bottleneck events throughout Europe, consistent with the reported overall demographic decline of the species during the past centuries. According to the genetic patterns observed in this study, management strategies aimed to halter the ongoing decline of the endangered European mink should promote gene flow among scattered populations in order to improve genetic connectivity.

\section{Methods}

\section{Sample collection}

A total of 344 hair and tissue (skin, muscle or liver) samples were obtained from mink captured for tracking purposes, from specimens in museum collections and from traffic-killed individuals in France $(n=76)$, Spain $(n=94)$, Russia $(n=89)$, Estonia $(n=3)$, Belarus $(n=28)$, and Romania $(n=54)$. The performed research did not involve any experiment with animals and complies with international ethic guidelines. Samples were either stored in $96 \%$ ethanol or frozen at $-20{ }^{\circ} \mathrm{C}$. For genetic analyses, each mtDNA and microsatellite data from all individuals were grouped according to i) their regional distribution (datasets I) into Northeastern Europe (NE; Russia, Belarus and Estonia), Southeastern Europe (SE; Romania), and Western Europe (W; France and Spain) or ii) their river drainage distribution (datasets II) into the Northern Dvina (Severnaya Dvina), Volga and Western Dvina (Zapadnaya Dvina) in Russia, Belarus and Estonia; the Danube in Romania; the Charentes, Garonne and Adour in France, and the Ebro and Cantabrian rivers in Spain (Fig. 1).

\section{DNA extraction and marker choice}

DNA was extracted through standard proteinase K/ phenol-chloroform procedures [46] or using the QIAGEN ${ }^{\circ}$ DNeasy Tissue Kit (Izasa, S. A., Barcelona).

\section{$m t D N A$}

A 614-bp fragment including the 3 '-end of the cytochrome $b$ gene, and the hypervariable region of the $\mathrm{mt}$ control region, was amplified using two PCR primers specifically designed for European mink according to the PCR conditions described in Cabria et al. [47]. Newly determined mtDNA sequences were deposited in GenBank under accession numbers EU548035-EU548051. Two mtDNA control region sequences of the polecat, Mustela putorius, retrieved from GenBank (AY962025 and AY962030 [48]) were used as outgroup taxa.

\section{Microsatellites}

A total of 11 polymorphic microsatellite loci were analyzed. Five specific loci (Mlut04, Mlut20, Mlut25, Mlut32 and Mlut35) were isolated directly from Mustela lutreola [12], whereas the rest were originally developed for Mustela erminea (Mer09, Mer22 and Mer41) and Neovison vison (Mvis22, Mvis72, Mvis75) [49]. The PCR conditions used are provided in Cabria et al. [12] and Cabria et al. [47]. Only individuals genotyped for nine or more loci were included in further genetic analyses. Microsatellites were amplified and genotyped anew from the samples of Michaux et al. (2005) to avoid potential cross calibration problems.

\section{Mitochondrial DNA analyses Population diversity and demographic analyses}

Sequences were aligned using default parameters of CLUSTALX v.2 [48] and further inspected by eye to maximize positional homology. Gapped positions were excluded from further analysis. Haplotype (H; [50]) and nucleotide ( $\Pi$; $[50])$ diversity values were estimated both globally and separately for each population using Arlequin v.3.1 [51]. To detect departures (e.g., selection, 
demographic expansions or contractions) from the neutral model (random evolution), Tajima's D [52], Fu's Fs [53] and $R_{2}$ [54] tests were performed using Arlequin v.3.1 and DNASP v.5 [55]. Statistical significance was tested by performing either 10,000 coalescent simulations in DNASP v.5 or 10,000 random permutations in Arlequin v.3.1. In addition, past population dynamic reconstructions were performed with Bayesian coalescentbased methods as implemented in BEAST v1.7.2 [56]. Bayesian skyline plots (BSPs) were generated using Markov chain Monte Carlo (MCMC) sampling to infer past changes in the effective population size $\left(\mathrm{N}_{\mathrm{e}}\right)$ of the Eastern (NE and SE) European mink populations (note that the W population has a single haplotype, which prevents further population genetic analyses). The models HKY + G [57] and F81 [58] were selected as best fit nucleotide substitution models for the NE and SE populations, respectively, using the Bayesian information criterion (BIC) as implemented in jModeltest v.0.1.1 [59, 60]. Simulations were run with a strict molecular clock using uniformly distributed priors. We used for clock calibration the divergence rate of $14.5 \% \mathrm{Myr}^{-1}$, which was estimated for the closely related $M$. erminea mtDNA complete cytochrome $b$ and partial control region genes [61]. A piecewise-constant model of population size was selected with 10 groups. MCMC tests were run for $2 \times 10^{8}$ iterations and sampled every 10,000 iterations with $10 \%$ discarded as burn-in. To assess the robustness of parameter estimates, two independent runs were performed with identical settings and combined with LogCombiner [56]. Tracer v.1.5 [56] was used to visualize MCMC output and check for convergence and fluctuation of MCMC chains. The Bayesian skyline reconstructions were generated using Tracer to assess effective population size over time $\left(\mathrm{N}_{\mathrm{e}} \mathrm{\tau}\right)$, median estimate, and $95 \%$ highest posterior density (HPD) limits. The generation time used to estimate the $\mathrm{Ne}$ was assumed to be one year [62].

\section{Population structure analysis}

Genetic structure among populations was determined by estimating pairwise differences between haplotypes. $\Phi$ statistics [63] were estimated using Arlequin v.3.1, and their significance was determined with 90,000 permutation tests. The hierarchical distribution of $\mathrm{mt}$ genetic variation among populations was determined using an analysis of molecular variance (AMOVA) as implemented in Arlequin v.3.1. We examined how genetic variation was partitioned between the two major geographical areas (Western and Eastern Europe), as well as considering the NE and SE regions separately. Significances of $\Phi$-statistics and of variance components were tested using 90,000 random permutations. In all multiple tests, $p$-values were adjusted using Bonferroni correction [64].

\section{Phylogenetic and network analyses}

All sequences were collapsed into distinct haplotypes using DNASP v.5 [55] and combined into a single data set. This data set was analyzed with three different methods of phylogenetic inference: Maximum Likelihood (ML; [58]) using PAUP v.4.0b10 [65], Bayesian inference (BI; [66]) using MrBayes v.3.2.0 [67] and coalescencebased methods using BEAST v.1.7 [56]. Best-fit models of nucleotide substitution were estimated using jModeltest based on Akaike information criteria (AIC) or BIC for the ML (TIM2 + I + G) and BI (HKY + G; [57] analyses, respectively. ML was performed using heuristic searches with 10 random addition and TBR branch swapping. BI was conducted as four simultaneous chains, each of $2 \times 10^{8}$ generations, sampled every 1000 generations (10\% of trees were discarded as burn-in). Robustness was assessed through non-parametric bootstrap [68] proportions (BPs; 1000 pseudoreplicates) and Bayesian posterior probabilities (BPPs), respectively. Coalescence-based phylogenetic inference was performed using MCMC sampling. Model HKY + I + G [57] was selected as the best fit nucleotide substitution using the Akaike information criterion (AIC) as implemented in jModeltest v.0.1.1 $[59,60]$. MCMCs were run for $2 \times 10^{8}$ iterations and sampled every 10,000 iterations with $10 \%$ discarded as burnin using TreeAnnotator. Different models of coalescence were applied as the tree prior to investigate consistency in the results. MCMC analyses were run for 20 million iterations and sampled every 2000 iterations. The reconstructed trees had the same $50 \%$ majority-rule consensus topology as shown in Fig. 2 (reconstructed using ML and BI; data not shown).

Intraspecific genetic variation was determined using two different networking approaches. First, mtDNA haplotypes were plotted on a median-joining (MJ) network applying NETWORK v.4.112 [46]. After network calculation, the MP option was applied for elimination of unnecessary median vectors [69]. We repeated the analyses varying the parameter epsilon (a weighted genetic distance measure), and no changes were observed in the reconstructed networks. A second haplotype network was constructed under parsimony with TCS v.1.21 [70].

\section{Microsatellite statistical analyses}

\section{Standard genetic variability analyses}

Genetic diversity was estimated per locus and per population based on total number of alleles $\left(\mathrm{N}_{\mathrm{A}}\right)$, private alleles, allelic diversity (A), as well as observed $\left(\mathrm{H}_{\mathrm{o}}\right)$ and expected $\left(\mathrm{H}_{\mathrm{e}}\right)$ heterozygosities [71] using FSTAT v.2.93 [72] and Genetix v.4.05 [73]. Deviations from HardyWeinberg equilibrium (HWE) for each locus and across 
all loci, as well as genotypic linkage disequilibrium between all pairs of loci were tested in GenePop v.4 [74]. Statistical significance was tested by running a Monte Carlo Markov Chain (MCMC) consisting of 10,000 batches of 10,000 iterations each, with the first 10,000 iterations discarded before sampling [75]. $P$-values were adjusted with Bonferroni procedures that correct for the effect of multiple tests [64]. In addition, the unbiased Wright inbreeding coefficient $F_{I S}$ [76] was used to define deviations from HWE.

The possible existence of null alleles and their frequencies were inferred using the EM algorithm [77] as implemented in FreeNA [78]. We also evaluated the impact of null alleles on the estimation of genetic differentiation. To estimate whether the analyzed microsatellite dataset provided sufficient statistical power to detect significant genetic differentiation, we used POWSIM [79]. Allele frequency homogeneity at each of the eleven loci, separately or combined, was assessed with Fisher's exact and traditional chi-squared tests. Results indicated that the probability of detecting population structure was high, and statistically significant (data not shown). When $\mathrm{F}_{\mathrm{ST}}$ was set to zero (which simulates no divergence among samples), the proportion of falsely significant values ( $\alpha$ type $I$ error) was in all cases lower than the intended value of $5 \%$.

\section{Bayesian clustering analyses}

Two different Bayesian clustering methods were used to determine the population structure of the European mink. First, we used STRUCTURE v2.2 [13]. The number of subpopulations $(k)$ was calculated with no prior population information and an admixture model. We performed 10 series of independent runs for $K$ from one to ten populations, setting default values with constant lambda $(\lambda)$ and the same alpha $(\alpha)$ values for all populations. MCMC consisted of $10^{5}$ burn-in iterations followed by $10^{6}$ sampled iterations. Further, the modal value of lambda, $\Delta k$ [14] was also calculated to infer the best value of $k$. Clusters were depicted using Distruct v.1.1 [80].

In addition, STRUCTURAMA v1.0 (http://fisher.berke ley.edu/structurama/) was used to verify congruence among results obtained with STRUCTURE, assuming that the number of populations is a random variable that follows a Dirichlet process prior [15]. The prior mean of the number of populations $(\alpha)$ was set as a random variable from 2 to 6 , and $10^{4}$ MCMC cycles were run.

Finally, a spatial analysis of molecular variance, (SAMOVA 1.0, [81], was used to define partitions of sampling sites that are maximally differentiated from each other without any a priori assumption about population structure. This method identifies $k$ genetically differentiated populations, where the proportion of total genetic variance $\left(\mathrm{F}_{\mathrm{CT}}\right)$ is maximized. The geographic coordinates for each region were calculated as the centre of the different localities. We tested a range of values of $k$ from 2 to 5 , using 100 simulated annealing steps.

\section{Population differentiation}

Genetic differentiation between populations was assessed based on two statistics: $\mathrm{F}_{\mathrm{ST}}$ (infinite allele model, IAM; [76]), and $\mathrm{R}_{\mathrm{ST}}$, (stepwise mutation model, SMM; [82]). The significance level was assessed by conducting 90,000 permutations, as implemented in the RstCalc package v.2.2 [83] and Arlequin v.3.1. An AMOVA test was performed to determine how genetic variation was partitioned within and among the same hierarchical scheme described above for mtDNA and the clusters inferred with STRUCTURE using Arlequin v.3.1. In all cases, $P$-values were adjusted using Bonferroni correction [64]. Patterns of genetic differentiation among all samples were visualized in a Factorial Correspondence Analysis (FCA) plot using Genetix v.4.05.

\section{Biogeographic analyses}

Approximate Bayesian Computation implemented in the DIYABC v.1.0.4 [84] was used to infer the colonization pathway of the European mink in Western Europe, as well as to assess how past/recent evolutionary history may have shaped the current genetic diversity and structure of the species, based on a comparison of a wide range of different colonization scenarios.

The biogeographic analyses were based on the microsatellite data set. We compared fourteen different biogeographic models assuming that NE and SE populations diverged from the same ancestral (source) population or from an admixture of two populations (Fig. 5). Because of constraints related to computational time, the space of all possible sequence of divergence could not be systematically explored. However, we tried to choose the most plausible scenarios on the basis of our knowledge of the European mink's biology and historical information concerning this species. For historical model parametrization, these scenarios were described as a succession of events including population divergence and admixture. The first 6 scenarios are characterised by 3 steps of separation: step 1: separation between populations $\mathrm{NE}$ and $\mathrm{SE}$; step 2: admixture between these populations; step 3: separation between populations FR and SP.

- Scenario 1 corresponds to a non-differentiation between the NE and SE populations at step 1, followed by an admixture at step 2 . This leads to a new lineage corresponding to the FR population, which diverge at step 3 to give the SP population. 
- Scenario 3 is similar to scenario 1 at the exception of step 2, which leads to a lineage corresponding the SP population. This will diverge at step 3 to give the FR population.

- Scenario 5 is also similar to scenario 1 but without differentiation between FR and SP populations at step 3 .

- Scenario 2, 4, and 6 propose similar divergence as compared to the last three scenarios, respectively, at the exception of a differentiation between NE and SE populations at step 1.

- Scenarios from 7 to 14 are also characterized by three steps of divergence, but without admixture processes. Each of these scenarios is characterized by different possibilities of divergence leading to the four existing mink populations, from the most ancient lineages corresponding to the NE and SE populations to the most recent ones (SP and FR).

A total of 14 million simulations were run, providing one million simulations for each scenario. The parameters of each model (i.e. population sizes, timings of demographic events, mutation rates) were considered as random variables drawn from prior distributions (see Additional file 8).

The posterior probability of each scenario was estimated using a polychotomous logistic regression [84, 85] on the $1 \%$ of simulated data sets closest to the observed data set, subject to a linear discriminant analysis as a pre processing step [86]. The selected scenario was that with the highest posterior probability value with a nonoverlapping $95 \%$ confidence interval.

\section{Availability of supporting data}

mtDNA sequences: GenBank accession numbers, EU5480 35 (Mlh1), EU548036 (Mlh2), EU548037 (Mlh3), EU548038 (Mlh4), EU548039 (Mlh5), EU548040 (Mlh6), EU548041 (Mlh7), EU548042 (Mlh8), EU548043 (Mlh9), EU548044 (Mlh10), EU548045 (Mlh11), EU548046 (Mlh12), EU548047 (Mlh13), EU548048 (Mlh14), EU548049 (Mlh15), EU548050 (Mlh16), EU548051 (Mlh17), Data sets used in this study were deposited in TreeBase (http://purl.org/phylo/treebase/ phylows/study/TB2:S17884).

\section{Additional files}

Additional file 1: Estimated $\Phi_{\text {ST }}$ values for mtDNA. Estimated $\Phi_{\text {ST }}$ values* for mtDNA obtained by comparing individuals grouped according to regional distribution (mtDNA dataset I) and drainage basin (mtDNA dataset II).

Additional file 2: Analysis of molecular variance (AMOVA) based on mtDNA data. $P$ values in bold indicate a significant difference.

Additional file 3: Estimates for $\mathbf{F}_{\mathbf{S T}}$ and $\mathbf{R}_{\mathbf{S T}}$. Estimates* for $\mathrm{F}_{\mathrm{ST}}$ (below diagonal) and $R_{\text {ST }}$ (above diagonal) between geographical region-pairs (microsatellite dataset I) and drainage basin pairs (microsatellite dataset II) from eleven microsatellite loci tested in European mink individuals. Values in bold indicate significance after sequential Bonferroni correction.
Additional file 4: Analysis of molecular variance (AMOVA) based on microsatellite data. Data represent eleven microsatellite loci. $P$ values in bold indicate a significant difference.

Additional file 5: Factorial correspondence analysis plot constructed by GENETIX using data for eleven microsatellite loci. The plot depicts multivariate relationships among the European mink sampled. Each axis displays total variation percentages in allele frequencies.

Additional file 6: Comparison of the posterior probabilities of all tested scenarios in the $A B C$ analysis using a polychotomous Logistic regression approach.

Additional file 7: Divergence time estimations for the main European mink's evolutionary steps, obtained with diyABC analyses.

Additional file 8: Model specification, prior distributions for demographic parameters and locus-specific mutation model parameters used for the diyABC analyses. Type of parameters: $(N)$ effective population size, ( $T$ ) time of the event in generation, (A) admixture. Uniform distribution (UN) with 2 parameters: min and max; Gamma distribution (GA) with 2 parameters: mean and shape. The mutation model parameters for the microsatellite loci were the mean mutation rate $\left(\mu_{\text {mic }}\right)$, the parameter determining the shape of the gamma distribution of individual loci mutation rate $(P)$, and the Single Insertion Nucleotide rate (SN)

\section{Competing interests}

The authors declare that they have no competing interests.

\section{Authors' contributions}

The authors of this paper have a general interest in the evolutionary mechanisms that generate biodiversity, phylogeny, phylogeography and conservation genetics, with particular emphasis on mammal species. For this paper, MTC and EGG were involved in obtaining the molecular data, and together with JRM in performing the population genetic analyses. DS, AK, PF and SP collected the samples. MTC, EGG, JRM, BJM, and RZ contributed equally to writing the manuscript and interpreting the genetic diversity, distribution pattern and evolutionary history of the critically endangered European mink Mustela lutreola. All authors read and approved the final manuscript.

\section{Acknowledgments}

The authors thank Gorka Belamendia, Joseba Carreras, Juan Carlos Ceña, Angus Davison, Mirenka Ferrer (TRAGSA), Asunción Gómez, Jorge González, Vladimir Katchanovsky, Luis Lobo, Javier López de Luzuriaga, Sisco Mañas, Tiit Maran, Javier Pinedo, Madis Pödra, Javier Zabala, Iñigo Zuberogoitia and the Wildlife Recovery Centres of Mártioda-Álava and Burgos (Castilla León) for providing the different mustelid samples. This work was partially funded by three LIFE projects ("Conservación del visón europeo (Mustela lutreola) en "Castilla León" LIFE 00/NAT/E7229, La Rioja" LIFE 00/NAT/E7331 and "Álava" LIFE 00/NAT/E7335), and grants from the Diputación Foral de Álava and the University of the Basque Country (GIU 06/09) awarded to BJGM. The Basque Government (BG) also financed this study (project numbers IT317-10; IT575-13). MTC had a fellowship from the BG.

\section{Author details}

${ }^{1}$ Departamento de Zoología y B.C.A., Facultad de Farmacia, Universidad del País Vasco UPV/EHU, Paseo de las Universidades, 7, 01006 Vitoria-Gasteiz, Spains. 'Laboratoire de Biologie Évolutive, Institut de Botanique (Bat.22), Université de Liège (Sart Tilman), Boulevard du Rectorat, 27, B4000 Liège, Belgium. ${ }^{3}$ Departamento de Biodiversidad y Biología Evolutiva, Museo Nacional de Ciencias Naturales, CSIC, José Gutiérrez Abascal, 2, 28006 Madrid, Spain. ${ }^{4}$ Centre de Biologie et de Gestion des Populations, CBGP, Campus international de Baillarguet, CS 30016, 34988 Montferrier-sur-Lez, Cedex, France. ${ }^{5}$ Russian Research Institute of Game Management and Fur Farming, Engels Street, 79, Kirov, Russia. Institute of Wildlife Biology and Game Management, BOKU University of Natural Resources and Life Sciences, Gregor Mendel Street 33, 1180 Vienna, Austria. 'Groupe de Recherche et d'Etudes pour la Gestion de l'Environnement (GREGE), Route de Préchac, 33730 Villandraut, France. ${ }^{8}$ Departament de Biologia Animal, Facultat de Biologia, Universitat de Barcelona, Diagonal 643, 2a planta, 08028 Barcelona, Spain. 
Received: 14 April 2015 Accepted: 2 July 2015

Published online: 17 July 2015

\section{References}

1. Davison A, Griffiths HI, Brookes RC, Maran T, Macdonald DW, Sidorovich VE, et al. Mitochondrial DNA and palaeontological evidence for the origins of endangered European mink, Mustela lutreola. Animal Conservation. 2000;3(4):345-55.

2. Youngman PM. Distribution and systematics of the European Mink, Mustela lutreola Linnaeus, 1761. Acta Zool Fenn. 1982;166:1-48.

3. Wozencraft WC. Carnivore behavior, ecology and evolution. Ithaca NY: Cornell University Press; 1989.

4. Koepfli KP, Deere KA, Slater GJ, Begg C, Begg K, Grassman L, et al. Multigene phylogeny of the Mustelidae: resolving relationships, tempo and biogeographic history of a mammalian adaptive radiation. BMC Biol. 2008;6:10.

5. Lode T, Cormier JP, Le Jacques D. Decline in endangered species as an indication of anthropic pressures: the case of European mink Mustela lutreola Western population. Environ Manage. 2001;28(6):727-35.

6. Maran T. Conservation biology of the European mink, Mustela lutreola (Linnaeus 1761): decline and causes of extinction. Tallinn, Estonia: Tallinn University Dissertations on Natural Sciences; 2007.

7. Rozhnov W. Extinction of the European mink: ecological catastrophe or a natural process? Lutreola. 1993;1:10-6.

8. Sidorovich VE, Macdonald DW, Kruuk H, Krasko DA. Behavioural interactions between the naturalized American mink Mustela vison and the native riparian mustelids, NE Belarus, with implications for population changes. Small Carnivore Conservation. 2000;22:1-5.

9. Mustela lutreola. In: IUCN Red List of Threatened Species Version 2012.2

10. Michaux JR, Hardy OJ, Justy F, Fournier P, Kranz A, Cabria M, et al. Conservation genetics and population history of the threatened European mink Mustela lutreola, with an emphasis on the west European population. Mol Ecol. 2005;14(8):2373-88.

11. Michaux JR, Libois R, Davison A, Chevret P, Rosoux R. Is the western population of the European mink, (Mustela lutreola), a distinct Management Unit for conservation? Biol Conserv. 2004;115(3):357-67.

12. Cabria MT, Gonzalez EG, Gómez-Moliner BJ, Zardoya R. Microsatellite markers for the endangered European mink (Mustela lutreola) and closely related mustelids. Mol Ecol Notes. 2007;7(6):1185-8.

13. Pritchard JK, Stephens M, Donnelly P. Inference of population structure using multilocus genotype data. Genetics. 2000;155(2):945-59.

14. Evanno G, Regnaut S, Goudet J. Detecting the number of clusters of individuals using the software STRUCTURE: a simulation study. Mol Ecol. 2005;14(8):2611-20.

15. Pella J, Masuda M. The Gibbs and split-merge sampler for population mixture analysis from genetic data with incomplete baselines. Can J Fish Aquat Sci. 2006;63:576-96.

16. Aguilar A, Jessup DA, Estes J, Garza JC. The distribution of nuclear genetic variation and historical demography of sea otters. Anim Conserv. 2008; 11:35-45.

17. Frantz AC, Pope LC, Etherington TR, Wilson GJ, Burke T. Using isolation-by-distance-based approaches to assess the barrier effect of linear landscape elements on badger (Meles meles) dispersal. Mol Ecol. 2010;19(8):1663-74.

18. Larson S, Jameson R, Bodkin J, Staedler M, Bentzen P. Microsatellite DNA and mitochondrial DNA variation in remnant and translocated sea otter (Enhydra lutris) populations. J Mammal. 2002;83:893-906.

19. Lecis R, Ferrando A, Ruiz-Olmo J, Mañas S, Domingo-Roura X. Population genetic structure and distribution of introduced American mink (Mustela vison) in Spain, based on microsatellite variation. Conserv Genet. 2008:9:1149-61.

20. Marmi J, Lopez-Giraldez F, Macdonald DW, Calafell F, Zholnerovskaya E, Domingo-Roura X. Mitochondrial DNA reveals a strong phylogeographic structure in the badger across Eurasia. Mol Ecol. 2006;15(4):1007-20.

21. Mucci N, Arrendal J, Ansorge H, Bailey M, Bodner M, Delibes M, et al. Genetic diversity and landscape genetic structure of otter (Lutra lutra) populations in Europe. Conserv Genet. 2010;11:583-99.

22. Pertoldi C, Breyne P, Cabria MT, Halfmaerten D, Jansman HAH, Van Den Berge $\mathrm{K}$, et al. Genetic structure of the European polecat (Mustela putorius) and its implication for conservation strategies. J Zool. 2006;270(1):102-15.
23. Wisely SM, Santymire RM, Livieri TM, Mueting SA, Howard JG. Genotypic and phenotypic consequences of reintroduction history in the black-footed ferret (Mustela nigripes). Conserv Genet. 2008;9:389-99.

24. Schmitt T. Molecular biogeography of Europe: Pleistocene cycles and postglacial trends. Front Zool. 2007:4:11.

25. Hewitt G. Post-glacial re-colonization of European biota. Biol J Linn Soc. 1999;68:87-112.

26. Schmitt T, Varga Z. Extra-Mediterranean refugia: The rule and not the exception? Front Zool. 2012;9(1):22.

27. Stewart JR, Lister AM. Cryptic northern refugia and the origins of the modern biota. Trends Ecol Evol. 2001;16:608-13.

28. Lagercrantz U, Ryman N. Genetic structure of Norway spruce (Picea abies) concordance of morphological and allozymic variation. Evolution. 1990:44:38-53.

29. Babik W, Branicki W, Sandera M, Litvinchuk S, Borkin L, Irwin JT, et al. Mitochondrial phylogeography of the moor frog, Rana arvalis. Mol Ecol. 2004;13(6):1469-80.

30. Stauffer C, Lakatos F, Hewitt GM. Phylogeography and postglacial colonization routes of Ips typographus L. (Coleoptera, Scolytidae). Mol Ecol. 1999;8(5):763-73.

31. Sommer R, Benecke N. Late- and Post-Glacial history of the Mustelidae in Europe. Mammal Rev. 2004;34:249-84.

32. Simakova AN. The vegetation of the Russian Plain during the second part of the Late Pleistocene (33-18 ka). Quatern Int. 2006;149:110-4

33. Velichko AA. The Pleistocene termination in Northern Eurasia. Quatern Int 1995;28:105-11.

34. Hewitt $\mathrm{G}$. The genetic legacy of the Quaternary ice ages. Nature. 2000;405(6789):907-13

35. Palazón S, Ruiz-Olmo J. Preliminary data on the use of space and activity of the European mink (Mustela lutreola) as revealed by radio-tracking. Small Carnivore Conservation. 1993;8:6-8.

36. Carbonell R. Managing Spanish European mink populations: Moving from a precautionary approach towards knowledge-based management. J Nat Conserv. 2015;25:58-61.

37. Clavero M. Shifting Baselines and the Conservation of Non-Native Species. Conserv Biol. 2014;28(5):1434-6.

38. DÍEz-LeÓN M, Miranda R, Ariño AH, Galicia D. Setting priorities for existing conservation needs of crayfish and mink. Conserv Biol. 2015;29(2):599-601.

39. Edmands $\mathrm{S}$. Between a rock and a hard place: evaluating the relative risks of inbreeding and outbreeding for conservation and management. Mol Ecol. 2007;16(3):463-75

40. O'Grady JJ, Brook BW, Reed DH, Ballou JD, Tonkyn DW, Frankham R. Realistic levels of inbreeding depression strongly affect extinction risk in wild populations. Biol Conserv. 2006;133:42-51.

41. Spielman D, Brook BW, Frankham R. Most species are not driven to extinction before genetic factors impact them. Proc Natl Acad Sci U S A. 2004;101(42):15261-4.

42. Frankham R, Ballou JD, Eldridge MDB, Lacy RC, Ralls K, Dudash MR, et al. Predicting the probability of outbreeding depression. Conserv Biol. 2011;25:465-75.

43. Frankham R. Genetics and extinction. Biological Conservation. 2005;126:131-40

44. Frankham R, Ballou JD, Briscoe DA. Introduction to conservation genetics. Cambridge: Cambridge University Press; 2002.

45. Spurgin LG, Richardson DS. How pathogens drive genetic diversity: MHC mechanisms and misunderstandings. Proceedings Biological sciences / The Royal Society. 2010;277:979-88.

46. Bandelt $\mathrm{HJ}$, Forster P, Rohl A. Median-joining networks for inferring intraspecific phylogenies. Mol Biol Evol. 1999;16:37-48.

47. Cabria MT, Michaux JR, Gomez-Moliner BJ, Skumatov D, Maran T, Fournier P, et al. Bayesian analysis of hybridization and introgression between the endangered european mink (Mustela lutreola) and the polecat (Mustela putorius). Mol Ecol. 2011;20:1176-90.

48. Larkin MA, Blackshields G, Brown NP, Chenna R, McGettigan PA, McWilliam $H$, et al. Clustal W and Clustal X version 2.0. Bioinformatics. 2007;23:2947-8.

49. Fleming MA, Ostrander EA, Cook JA. Microsatellite markers for American mink (Mustela vison) and ermine (Mustela erminea). Mol Ecol. 1999;8:1352-4.

50. Nei M. Molecular evolutionary genetics. New York, USA; 1987.

51. Excoffier L, Laval G, Schneider S. Arlequin (version 3.0): an integrated software package for population genetics data analysis. Evol Bioinform Online. 2005;1:47-50. 
52. Tajima F. Statistical method for testing the neutral mutation hypothesis by DNA polymorphism. Genetics. 1989;123:585-95.

53. Fu YX. Statistical tests of neutrality of mutations against population growth, hitchhiking and background selection. Genetics. 1997:147:915-25.

54. Ramos-Onsins S, Rozas J. Statistical properties of new neutrality tests against population growth. Mol Biol Evol. 2002;19:2092-100.

55. Librado P, Rozas J. DnaSP v5: a software for comprehensive analysis of DNA polymorphism data. Bioinformatics. 2009;25:1451-2.

56. Drummond AJ, Suchard MA, Xie D, Rambaut A. Bayesian phylogenetics with BEAUti and the BEAST 1.7. Mol Biol Evol. 2012;29:1969-73.

57. Hasegawa M, Kishino H, Yano T. Dating of the human-ape splitting by a molecular clock of mitochondrial DNA. J Mol Evol. 1985;22(2):160-74.

58. Felsenstein J. Evolutionary trees from DNA sequences: a maximum likelihood approach. J Mol Evol. 1981;17:368-76.

59. Guindon S, Gascuel O. A simple, fast, and accurate algorithm to estimate large phylogenies by maximum likelihood. Syst Biol. 2003;52:696-704.

60. Posada D. JModelTest: phylogenetic model averaging. Mol Biol Evol. 2008;25:1253-6.

61. Martinkova N, McDonald RA, Searle JB. Stoats (Mustela erminea) provide evidence of natural overland colonization of Ireland. Proceedings Biological sciences / The Royal Society. 2007;274(1616):1387-93.

62. Macdonald DW, Sidorovich VE, Maran T, Kruuk H. The Darwin initiative. European mink, Mustela lutreola: analyses for conservation. 2002.

63. Excoffier L, Smouse PE, Quattro JM. Analysis of molecular variance inferred from metric distances among DNA haplotypes: application to human mitochondrial DNA restriction data. Genetics. 1992;131:479-91.

64. Rice WR. Analyzing tables of statistical tests. Evolution. 1989;43:223-5.

65. Swofford DL. PAUP*: Phylogenetic analysis using parsimony (*and other methods), version 4.0b 10. 2002.

66. Huelsenbeck JP, Ronquist F, Nielsen R, Bollback JP. Bayesian inference of phylogeny and its impact on evolutionary biology. Science. 2001;294:2310-4

67. Ronquist F, Teslenko M, van der Mark P, Ayres DL, Darling A, Höhna S, et al. MrBayes 3.2: Efficient Bayesian phylogenetic inference and model choice across a large model space. Systematic Biology. 2012;3:539-42.

68. Felsenstein J. Confidence limits on phylogenies: an approach using the bootstrap. Evolution. 1985;39:783-91.

69. Polzin T, Daneschmand SV. On Steiner trees and minimum spanning trees in hypergraphs. Oper Res Lett. 2003;31:12-20.

70. Clement M, Posada D, Crandall KA. TCS: a computer program to estimate gene genealogies. Mol Ecol. 2000;9:1657-9.

71. Nei M. Estimation of average heterozygosity and genetic distance from a small number of individuals. Genetics. 1978;89:583-90.

72. Goudet J. FSTAT (Version 1.2): A computer program to calculate F-statistics. J Hered. 1995;86:485-6.

73. Belkhir K, Borsa P, Chikhi L, Raufaste N, Bonhomme F. Genetix 4.02, Logiciel sous windows pour la génétique des populations. In: Montpellier (France): Laboratoire Genome, Populations, Interactions, CNRS UMR 5000, Universite de Montpellier II. 2000.

74. Raymond M, Rousset F. GENEPOP (version 1.2): population genetics software for exact tests and ecumenicism. J Hered. 1995;86:248-9.

75. Guo SW, Thompson EA. Performing the exact test of Hardy-Weinberg proportion for multiple alleles. Biometrics. 1992:48:361-72.

76. Weir BC, Cockerham CC. Estimating F-statistics for the analysis of population structure. Evolution. 1984;38:1358-70.

77. Dempster AP, Laird NM, Rubin DB. Maximum likelihood from incomplete data via EM algorithm. J Roy Stat Soc B Met. 1977;39:1-38.

78. Chapuis MP, Estoup A. Microsatellite null alleles and estimation of population differentiation. Mol Biol Evol. 2007;24:621-31.

79. Ryman N, Palm S. POWSIM: a computer program for assessing statistical power when testing for genetic differentiation. Molecular Ecology Notes. 2006;6:600-2.

80. Rosenberg NA. Distruct: a program for the graphical display of population structure. Mol Ecol Notes. 2004:4:137-8.

81. Dupanloup I, Schneider S, Excoffier L. A simulated annealing approach to define the genetic structure of populations. Mol Ecol. 2002;11(12):2571-81.

82. Slatkin M. A measure of population subdivision based on microsatellite allele frequencies. Genetics. 1995;139:457-62.

83. Goodman SJ. RST Calc: a collection of computer programs for calculating estimates of genetic differentiation from microsatellite data and determining their significance. Mol Ecol. 1997;6:881-5.
84. Cornuet JM, Santos F, Beaumont MA, Robert CP, Marin JM, Balding DJ, et al. Inferring population history with DIY ABC: a user-friendly approach to approximate Bayesian computation. Bioinformatics. 2008;24:2713-9.

85. Cornuet JM, Ravigne V, Estoup A. Inference on population history and model checking using DNA sequence and microsatellite data with the software DIYABC (v1.0). BMC Bioinformatics. 2010;11:401.

86. Estoup A, Lombaert E, Marin JM, Guillemaud T, Pudlo P, Robert CP, et al. Estimation of demo-genetic model probabilities with Approximate Bayesian Computation using linear discriminant analysis on summary statistics. Mol Ecol Resour. 2012;12(5):846-55.

\section{Submit your next manuscript to BioMed Central and take full advantage of:}

- Convenient online submission

- Thorough peer review

- No space constraints or color figure charges

- Immediate publication on acceptance

- Inclusion in PubMed, CAS, Scopus and Google Scholar

- Research which is freely available for redistribution 